УДК 627.8.059: 550.8.04

\title{
ИССЛЕДОВАНИЕ АВАРИЙ НА ГИДРОТЕХНИЧЕСКИХ СООРУЖЕНИЯХ И МЕТОДЫ КОНТРОЛЯ ИХ БЕЗОПАСНОСТИ
}

\author{
Ахметов Ермек Мауленович1, \\ aem.47@mail.ru \\ Асемов Камбар Мустафаевич1, \\ kassemov@kazkern.kz \\ Жуматаева Марина Оразовна", \\ j.marina07@rambler.ru \\ 1 Национальный центр по комплексной переработке минерального сырья Республики Казахстан, \\ Казахстан, A10M6G5, г. Алматы, ул. Жандосова, 67.
}

Актуальность исследования. На сегодняшний день проблемы безопасности объектов водного хозяйства, в особенности плотин, дамб и других гидротехнических сооружений, остро стоят в обществе. Это связано, прежде всего, с большими экономическими, экологическими и социальными потерями, к которым приводят разрушения подобных объектов. В этой связи очевидна необходимость максимального снижения вероятности таких событий. Этот вывод в полной мере относится и к гидротехническим сооружениям в Республике Казахстан, большинство которых были построены в 60-80 г2. прошлого столетия и были случаи возникновения аварийных ситуаций. Наиболее значимые из них - прорыв земляных плотин в Кызылагаше в 2010 г. и в Кокпекты в 2014 г. В последнее время интенсивное развитие стало получать применение новых инновационных методов контроля за гидротехническими сооружениями, в том числе геосизических методов. Интерпретация результатов геофизических измерений может более детально охарактеризовать строение и физико-механические свойства пород, слагающих тело земляных плотин. В этом заключается актуальность данной работы, которую можно считать базой для проведения дальнейших исследований и применения геофизических методов на плотинах земляного типа в Республике Казахстан.

Цель: выбор оптимального комплекса геофизических методов для последующего опробования их на гидротехнических сооружениях земляного типа.

Объектом исследования являются причины аварий на гидротехнических сооружениях и методы контроля за их состоянием. Методика: проведение анализа причин разрушений гидротехнических сооружений, анализ информативности геофризических методов при изучении строения плотин с обоснованием оптимального комплекса для диагностики и прогнозирования технического состояния земляных плотин.

В результате исследования выбран оптимальный комплекс геофизических методов: электрическая и сейсмическая разведка, георадарное зондирование. Данньй комплекс будет в дальнейшем опробован на плотинах земляного типа.

\section{Ключевые слова:}

Гидротехнические сооружения, безопасность, методы контроля, геофизические методы, оптимальный комплекс, земляные плотины в Республике Казахстан, базы данных.

\section{Введение}

Объекты, применяемые в водном хозяйстве, называются гидротехническими сооружениями (ГТС). Гидротехнические сооружения классифицируются на следующие типы: плотины, здания гидроэлектростанций, водосбросные, водоспускные и водовыпускные сооружения, туннели, каналы, насосные станции, судоходные шлюзы, судоподъемники, доки; сооружения, предназначенные для защиты от наводнений и разрушений берегов морей, озер и водохранилищ, берегов и дна русел рек; сооружения (дамбы), ограждающие золошлакоотвалы и хранилища жидких отходов промышленных и сельскохозяйственных организаций и другие, целевое назначение которых направлено на защиту от отрицательного действия вод и жидких отходов [1].

В литературе [2] приводится, что порядка 52 тыс. высоких плотин относятся к постройкам прошлого столетия, в том числе около 40 тыс. после 1950 г. Данное количество намного превышает число построек по сравнению с предшествующими 5000 лет. На данный момент с помощью водохранилищ регулируется более 10 тыс. км ${ }^{3}$ речных вод из общего объема 38,3 тыс. км ${ }^{3}$. Вода водохранилищ применяется для полива 270 млн га сельскохозяйственных земель, выработки 2460 млрд кВт.ч энергии (20 \% всей потребляемой энергии), для снабжения питьевой и технической водой, также на берегах водохранилищ строят здания различного назначения. В пяти наиболее развитых странах мира находится $3 / 4$ общего количества ГТС, из которых 79 \% высотой не более 30 м, а всего $1 \%$ выше 100 м (энергетические сооружения) [2]. Эти данные свидетельствует о крайней важности гидротехнических сооружений для хозяйственной деятельности. При этом обеспечение безопасности и устойчивости ГТС есть главный критерий при постройке плотин, являющихся потенциально опасными гидродинамическими сооружениями. Здесь же приводятся случаи аварий на крупных плотинах мира, которые привели к катастрофическим последствиям: человеческим жертвам, экономическому, экологическому и социальному урону, убыткам и ущербам. 
В различных странах, как и в Казахстане, периодически происходят аварии на ГТС. Анализируя крупные из них, можно сказать, что это происходит по причине нарушения норм и правил безопасности ГТС в процессе проектирования, строительства и эксплуатации, ненадлежащей организации надзора за безопасной эксплуатацией сооружений, недостатка квалифицированных специалистов и др. [2].

Систематический мониторинг ГТС, основанный на детальном обследовании, дает возможность заблаговременно выявить деструктивные зоны и элементы в теле сооружений, что позволит принять превентивные меры для предотвращения аварий. Для этих целей необходимо усовершенствование методов контроля, основанных на использовании инновационных научных разработок и современных аппаратурных средств.

\section{Анализ причин разрушений ГТС в зависимости от их конструктивных особенностей, возраста и условий эксплуатации, в том числе в Республике Казахстан}

Исследователями по использованию ГТС для хозяйственной деятельности отмечается важность обеспечения устойчивости и безопасности ГТС при разработке проектов на всех стадиях строительства сооружений и текущего ремонта и реконструкции этих объектов. Как показывает опыт эксплуатации, эффективность проектных решений может быть недостаточно высокой, если не будут применяться современные технологии мониторинга состояния ГТС для надёжной и безопасной эксплуатации на достаточно высоком техническом и организационном уровне.

В современном Казахстане, по данным источника [3], находятся 1665 ГТС. Из них 319 водохранилищ объемом более 1,0 км³, 443 плотины, 125 дамб и 778 других ГТС. Стратегически важными объектами являются 57 водохранилищ и 29 подпорных ГТС. В общей сложности из общего числа ГТС проведено обследование всего 1212 сооружений (73 \%). Результаты обследования говорят об удовлетворительном состоянии всего 865 (52 \%) объектов, остальным требуется ремонт. В основном сооружения находятся в эксплуатации свыше 30-50 лет с момента их строительства. Диагностика этих сооружений показало износ более $60 \%$, что снижает устойчивость ГТС.

В источнике [4] отмечено, что в настоящее время в Казахстане не существует специального законодательства, регулирующего вопросы обеспечения безопасности ГТС. Водный кодекс Республики Казахстан является главным правовым документом в вопросах регулирования использования водных ресурсов. Также указывается, что на сегодняшний день стоит острая необходимость разработки и принятия законодательного документа по безопасности ГТС, который отрегулирует многие правовые аспекты по обеспечению безопасности ГТС, работам, связанным с реконструкцией существующих и строительству новых объектов водного хозяйства, привлечению инвестиций, включая зарубежные [4]. Также данный документ позволит решить межгосударственные вопросы эффективного пользования вод трансгранич- ных рек и сохранения экологически равновесного состояния водных бассейнов.

Причинами морального и физического износа всего комплекса ГТС являются большой период пользования и малый объем финансирования на эксплуатационные расходы, текущие и капитальные ремонты, а также влияние климатических и сейсмических факторов. Близкое расположение к вредным производствам также является потенциальной угрозой безопасности ГТС.

Ниже представлены примеры прорыва плотин и их причины в Казахстане за последние 10 лет [3]:

- 2009 г. В результате обильных дождей и плохого состояния ирригационной системы была прорвана плотина в Шардаринском районе Туркестанской области, затоплению подверглись более 1000 домов, школа, больница и другие здания;

- 2010 г. Жертвами разрушения плотины в с. Кызылагаш Алматинской области и последующего паводка стали 43 человека, в т. ч. дети; ранено более 300 человек; разрушено и повреждено 440 домов;

- 2010 г. Разрушение береговой шпоры р. Каратал в Алматинской области привело к подтоплению 38 домов села Еркино;

- 2010 г. В результате увеличения уровня воды в p. Усек Алматинской области произошел прорыв плотины, эвакуировано более 2 тысяч жителей с. Лесновка;

- 2014 г. Быстрое таяние снега привело к переполнению водохранилища и разливу р. Сырдарья в Кызылординской области, были подтоплены 3 поселка: Жанакорган, Бирлик, Жайылма;

- 2014 г. Разрушение плотины Кокпектинского водохранилища в Восточно-Казахстанской области привело к гибели 5 человек и подтоплению п. Кокпекты;

- 2014 г. Размыв плотины в с. Жумабек Карагандинской области;

- 2014 г. Из-за обильных дождей произошел прорыв плотины в Талгарском районе Алматинской области;

- 2015 г. В результате резкого весеннего потепления произошел прорыв на нескольких плотинах в Карагандинской области.

Для осознания факторов, приводящих к аварийным ситуациям на ГТС, необходимо проведение анализа причин разрушений ГТС и закономерностей возникновения рисковых ситуаций. Если плотина находится в критическом состоянии, необходимо принять меры для предотвращения и смягчения последствий возможных стихийных бедствий. Следовательно, необходимо твердое понимание причин разрушения плотин (например, способы разрушения, ключевые факторы, влияющие на состояние плотин).

Учеными из Китайской Народной Республики были проведены статистические анализы информации о разрушениях плотин [5]. Из литературных данных накоплена и скомпонована информация о более 900 случаев разрушения различных плотин по всему миру, включающих земляные, бетонные, кладочные и насыпные [6, 7]. 
Детально собирались характеристики плотин и информация о разрушениях. В общей сложности были проанализированы 593 случая разрушения земляных плотин четырех основных категорий: однородные земляные плотины, неоднородные земляные плотины, земляные плотины с диафрагмами, грунтовые плотины, облицованные бетоном.

Сравнительный анализ случаев разрушения различных типов плотин в процентном соотношении показывает, что $66 \%$ случаев разрушения происходят с земляными плотинами. Если подойти к вопросу зависимости разрушения от высоты земляных плотин, то более половины составляют сооружения высотой менее 15 м. Очевидно, земляные плотины небольшой высоты имеют относительно более высокую вероятность разрушения.

Также рассматривалась связь разрушений с возрастом или сроком эксплуатации земляных плотин в момент их разрушений. Результаты анализа свидетельствуют, что плотины наиболее склонны к разрушению в их первый пятилетний срок эксплуатации $(30,5 \%)$, особенно в первый год после строительства $(14,2 \%)$. В промежуток 5-10 лет наступает «период затишья»; 10,5 \% составляют плотины, разрушившиеся в возрасте 10-20 лет и 9,8\% - в возрасте 20-40 лет. Видимо, это связано физическим и моральным старением плотины.

Исследованиями [8-10] были определены множество причин разрушений, но назвать единственную причину очень затруднительно. Часто несколько причин взаимосвязаны друг с другом. Выделяется четыре категории основных причин аварии: перелив, проблемы с состоянием плотины, плохое управление и стихийные бедствия. Перелив связан с недостаточной пропускной способностью сооружения, экстремальным наполнением, превышающим проектные параметры водохранилища. К категории «проблемы с состоянием плотины» относятся: «водопроводящие каналы» в основании и в теле плотины, сдвиг тела плотины, «водопроводящие каналы» вокруг водосброса, состояние водосбросных устройств, «водопроводящие каналы» вокруг водопропускных труб и других встроенных конструкций. Здесь необходимо обратить внимание, что «водопроводящий канал» является общим термином, который описывает механизмы, связанные с просачиванием воды. Плохое управление - снижение пропускной способности водохранилища из-за чрезмерного заполнения до наводнения, плохое обслуживание и эксплуатация, несвоевременное удаление временного усиления гребня водослива, организационные проблемы, отсутствие ответственных лиц за управление плотиной. И наконец стихийные бедствия - землетрясение, война и террористическая атака, пробой защитной плотины и т. п.

Установлено, что большинство случаев аварий вызвано либо переполнением, либо проблемами технического состояния плотин. Эти две причины привели почти к 80 \% всех разрушений плотин.
Очевидно, что основным фактором, влияющим на перелив через верх плотины, является недостаточность пропускной способности водосброса, что приводит к переполнению, особенно в сезон наводнений, и поэтому наиболее потенциально опасное место находится на водосбросе. Что касается «водопроводящего канала» в теле или основании плотины, то самым неблагоприятным фактором является трещина, которая может быть вызвана неравномерной осадкой, усадкой материала, дефектами основания и несовершенными стыками.

Таким образом, анализ вышеприведенных данных свидетельствует о том, что потенциально опасными местами плотины являются:

- основание плотины, что связано с оседанием гребня плотины, при этом уменьшается надводный борт, а это оседание часто связано с некачественным основанием;

- нисходящий склон плотины и эрозия материала нисходящего склона с течением времени, которая определяет, разрушится ли плотина в конечном счете или нет;

- водосброс, когда недостаточная пропускная способность водосброса является основной причиной переполнения, а переполнение и последующие разрушения плотин часто происходят в сезон наводнений.

Обобщенный анализ причин аварий на ГТС показывает, что они, являясь потенциально опасными объектами, требуют постоянного мониторинга их технического состояния всеми доступными методами и средствами с целью определения их устойчивости и безопасности.

Во многих странах мира приняты законодательные документы о безопасности ГТС, согласно которым организации, эксплуатирующие ГТС, составляют Декларацию безопасности для получения от уполномоченных органов разрешения на эксплуатацию сооружений. Это общепринятая международная практика.

Заключения, сделанные на основе анализа произошедших случаев прорывов ГТС, наводнений, подтоплений огромных районов в Казахстане, выявили, что в Казахстане не существует законодательных норм, включая Водный кодекс, которые обеспечили бы системную работу по организации безопасной эксплуатации плотин, предупреждению и ликвидации аварийных ситуаций на ГТС. Имеется только Приказ Министра сельского хозяйства от 2 декабря 2015 года № 19/1054, которым утверждены «Правила, определяющие критерии отнесения плотин к декларируемым» и «Правила разработки декларации безопасности плотины». Следовательно, вопрос государственного регулирования обеспечения безопасности ГТС является одним из принципиально важных. Кроме того, так как при чрезвычайных происшествиях с масштабными потерями, безусловно, будут правовые конфликты, для их разрешения также необходимы соответствующие законы и подзаконные акты. 
Одной из важных причин аварий ГТС в республике является несвоевременное выполнение восстановительно-ремонтных работ, которые не проводятся из-за отсутствия финансирования или недостаточной информации о внутреннем физическом состоянии ГТС. Получение данной информации не обеспечивается в необходимом объеме применением гидрогеологических и инженерно-геологических методов и к тому же сопряжено с большим объемом буровых работ.

Согласно действующим в Казахстане и в ряде стран СНГ Правилам технической эксплуатации, надзор за техническим состоянием ГТС проводится в виде натурных наблюдений геодезическими методами, визуально, также посредством контрольноизмерительных приборов [11]. Натурные наблюдения являются обязательной и важной частью декларации безопасности ГТС.

При визуальных наблюдениях осмотры основных конструкций объектов и близлежащих территорий проводятся регулярно в целях определения состояния ГТС, обнаружения дефектов и разрушительных процессов, понижающих надежность ГТС, а также для выявления необходимости в том или ином виде ремонтных работ [12].

Методика проведения визуальных и натурных наблюдений ГТС изложена достаточно подробно в работах [12-14]. Однако некоторые вопросы, возникающие при обследовании ГТС, требуют целого ряда специальных исследований. Определение геометрических параметров сооружения и его осадки не является особенно сложным в отличие от весьма затруднительного определения суффозионных и увлажненных зон, порового давления и проникновения различных флюидов в основание и тело земляных плотин.

\section{Анализ информативности геофизических методов и их комплексного применения при изучении строения плотин и прогнозировании их состояния}

Известно, что искусственные водохранилища существенно влияют на динамическое состояние земной коры и изменяют физические свойства среды. Вопрос изучения динамических процессов можно решить посредством исследования изменения физических полей, создаваемых породами, составляющими тело плотины. Интерпретация этих полей позволит получить количественную характеристику об объекте, описывающую его физические и геометрические параметры. Геофизические методы позволяют определить эти параметры. При этом разработанные методические данные по геофизическому мониторингу необходимо использовать при оценке состояния и устойчивости, безопасности ГТС в помощь натурному наблюдению и визуальному осмотру. Необходимо отметить, что любое ГТС характеризуется своими параметрами и оптимальный состав геофизических методов зависит от конкретных характеристик ГТС.

Для оценки устойчивости и прогноза физического состояния ГТС большую перспективу имеет интенсивно развиваемое в последнее время применение геофизических методов неразрушающего наблюдения.
В этом направлении большой вклад внесли российские исследователи [15-19].

С целью выявления структурного строения и физико-механических свойств (ФМС) грунтов тела плотины авторы [15-18] усовершенствовали технологии проведения комплекса сейсморазведочных и электроразведочных исследований. Для этого авторы исследований $[15,16]$ рассматривали вопросы:

- разработки сейсмогеологической модели ГТС на базе библиографических данных и параметрического бурения по исследуемому району;

- численного моделирования и оценки сейсмических методов для определения структуры и ФМС грунтов тела плотины;

- исследования состояния грунтов насыпных плотин с использованием сейсморазведочных методов для разработки определенной методики и соответствующей технологии с дальнейшим их апробированием на практике.

Авторами проведен анализ применяемых методов сейсмической разведки и выполнено моделирование с использованием компьютерной программы моделирования упругих волн FModel. Результаты моделирования выявили высокую эффективность метода при выделении деструктивных элементов в теле пятислойной модели. Вместе с тем авторы указывают на затруднения во время отработки и корреляции материалов, например, выявления преломляющих границ по первому вступлению. Предлагают способ, посредством которого можно разделить преломленные волны во вступлениях.

Опытно-методические исследования проводились на одном из ГТС разными способами мониторинга, где глубина изучаемого разреза составляла 15-20 м. Отрабатывались разные системы мониторинга методом преломленных волн (МПВ) и методом отраженной волны (МOB) - точка возбуждения, точка приема, шаги дискретизации и длина записи. По результатам исследовании авторы не смогли прийти к единому решению по выбору метода по причине присутствия интенсивных поверхностных волн. Проведя численное моделирование обоими методами, авторы приходят к мнению, что оба метода уверенно определяют скоростные характеристики геологического разреза ГТС. Отмечается, что при выявлении ФМС грунтов плотины применима одна ситуация - грунтовая наружность. При этом потребуется дополнительная информация, материалы микросейсмического и акустического каротажа. Даже при отсутствии этих данных необходим априорный геологический материал. Для детализации характера изменения ФМС внутри сейсмических слоев построены графики изменения физических параметров.

Таким образом, авторы на основе численного моделирования и опытно-методических работ решили нижеследующие задачи: на основе анализа строения грунтовых плотин края и априорных данных составлена сейсмогеологическая модель; исследованы особенности выполнения инженерных сейсморазведочных исследований для грунтовых плотин; решением 
прямой задачи определена структура волновых полей; дана оценка результативности сейсморазведочных работ; экспериментальными работами с различными системами наблюдений для плотин с глубиной 15-20 м подобран наиболее рациональный метод исследования. Разработанная методика сейсморазведочных работ была применена при исследовании ГТС Пермского края (Российская Федерация).

В $[17,18]$ авторы рассматривали вопрос разработки методики и технологии оперативного контроля устойчивости и прогноза технического состояния нескольких земляных плотин для того же Пермского края, но уже с применением комплекса геофизических методов. Выбран комплекс геофизических методов - метод электрического зондирования (ВЭЗ), метод естественного электрического поля (ЕП), метод георадиолокационного зондирования, сейсморазведочный метод, использующий преломленные волны продольного и поперечного типа. Авторами в результате изучения структурного строения по параметрическим инженерно-геологическим скважинам грунтовых дамб была построена обобщенная физикогеологическая модель. Затем было выполнено численное решение с помощью специальных программ. Результаты моделирования показали уверенное дифференцирование разреза, и были определены потенциально рисковые зоны, их отличие по физическим характеристикам. Например, увлажненные зоны отличаются более низкими величинами удельного электрического сопротивления.

Отмечается, что по результатам физикогеологического моделирования по сейсмическим данным можно выделить грунты с низкими упругими свойствами. Полученные экспериментальные исследования волнового поля достаточно хорошо проявляются и во временном разрезе. Результаты сравнивались с данными параметрического бурения и дали положительную оценку применения сейсмических методов для определения состояния сооружения и ФМС грунтов.

По данным количественной интерпретации составлен шестислойный геоэлектрический разрез, подтверждающий типовую модель плотины. Данные ВЭЗ позволили определить области низких электрических сопротивлений, связанных с зонами повышенной влажности.

Таким образом, результаты исследований показали, что результаты сейсмической разведки и георадарного зондирования хорошо отображают структурное строение, а методы электрической разведки водонасыщенность пород и зоны фильтрации.

Авторы работ [15-18] подготовили научнообоснованную методику и технологию применения инженерно-геофизического комплекса для оценки технического и физического состояния ГТС.

Коллективом исследователей в 2002-2012 гг. проводились наблюдения динамики изменения физических параметров плотины Иркутской ГЭС (Российская Федерация) комплексными геофизическими методами [19]. Сравнение результатов разных методов показывает, что отличие в них небольшое, т. е. в пределах погрешности интерпретации. В данных электроразведочных наблюдений не все однозначно. Повышения и понижения во времени электрического сопротивления объясняются повышением минерализации грунтовых вод и нарастанием фильтрации. Сравнение данных ВЭЗ с данными скважинных исследований показало, что данные работы являются перспективными для сбора данных, проведения различных расчетов устойчивости плотины, включая режимный мониторинг методом ЕП. При этом авторы связывают эпизодические отрицательные аномалии в ядре плотины с пористостью, водонасыщенностью и фильтрационными процессами.

В работе [20] для контроля за состоянием ГТС применили неразрушающий комплекс геофизических методов, таких как метод сопротивлений, георадарные исследования и электромагнитная проводимость. В качестве объекта опытных исследований и оценки возможности вышеназванных методов была выбрана старая дамба небольшой высоты (Чешская Республика), построенная еще в XV в., причем на дамбу отсутствовала документация о строении. Земляная насыпная дамба прошла реконструкцию в 2013 г. Дамба исследовалась двумя профилями, первый профиль продольный по верху дамбы по всей ее длине, второй - поперечный по простиранию дамбы.

Решались следующие задачи: определение основания дамбы и его однородность; определение по физическому полю исходного материала дамбы и добавленных при реконструкции материалов; выявление увлажненных зон в теле дамбы; сравнение методов по определению технического состояния дамбы.

По результатам геофизических исследований авторы отмечают следующее:

- по данным метода сопротивлений, т. е. по повышенным значениям кажущегося удельного электрического сопротивления $\left(\rho_{\kappa}\right)$, достаточно хорошо выделяется основание плотины, скорее всего сложенное валунно-галечными отложениями;

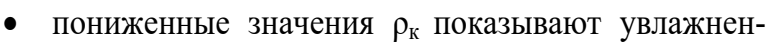
ные зоны в теле дамбы, причем четко выделяются старые и новые породы по относительно пониженным и повышенным значениям кажущегося сопротивления;

- только по поперечному профилю определяется предполагаемое направление конуса стока депрессионной зоны;

- менее информативными оказались георадарные исследования, но вместе с тем они достаточно хорошо выделяют приповерхностные увлажненные зоны.

Наиболее глубинным и информативным, по утверждению авторов, оказались методы сопротивления и электропроводимости.

В работе [21] рассматривается использование геофизических методов для обнаружения потенциальных зон утечек, которые могут поставить под угрозу целостность насыпной плотины Витиневского водохранилища (Чешская Республика) с риском для населе- 
ния. Для сопоставления данных и их оценки использовались три геофизических метода: электромагнитное профилирование, метод сопротивлений и метод ЕП.

Электромагнитные исследования проводились с целью быстрого сканирования всей площади плотины водохранилища. Генератор частоты передаёт синусоидное магнитное поле вертикальной/горизонтальной дипольной ориентации в различных частотах (6525, $13,025,27,025$ и 47,025 Гц). Приемник с такой же дипольной ориентацией принимает вторичное поле. Полученное вторичное магнитное поле состоит из мнимой части (противофазы), которая пропорциональна проводимости среды. Результаты сканирования приводятся в виде изолинии кажущегося удельного электрического сопротивления Ом/м, а не См/м. Полученные данные в дальнейшем проверялись данными кажущего электрического сопротивления и естественного электрического поля. Удельное электрическое сопротивление в исследуемом участке варьирует в пределах 20-50 Ом/м, что соответствует песчанистой глине и суглинку. Общее снижение 8-24 Ом/м на выделенном участке по данным сканирования авторы интерпретируют как водонасыщенные зоны, представляющие области высокого риска. В средней части плотины режимные наблюдения (при полном и пустом резервуape) методом естественного электрического поля проводились для подтверждения аномальных значений проводимости. Результаты подтвердили, что в зоне аномального значения проводимости выявлены участки с повышенной водонасыщенностью. Метод электромагнитного зондирования позволил определить слабые места, связанные с проводимостью. Эти результаты в дальнейшем использовались для применения метода сопротивлений и ЕП. Комплексная интерпретация всех трех методов позволила выявить ослабленные места в теле плотины.

Обзор методов для определения ослабленных зон в теле плотины представлен в [22]. Для этого предлагаются геофизические методы, например методы сопротивления, естественного электрического поля и электромагнитные методы.

Для определения состояния пород, слагающих земляную дамбу Адо-Экити в Юго-Западной Нигерии, был применен комплекс геофизических методов, таких как: метод сопротивлений и метод естественного электрического поля [23]. По результатам данных ВЭЗ составлен геоэлектрический разрез, показывающий структурное строение дамбы. Результаты интерпретации показывают, что верхняя часть дамбы сложена песчано-галечными породами, значение удельного сопротивление колеблется в пределах от 38-369 Ом*м с толщиной 1,2-2,7 м. Ядро дамбы сложено породами с удельным сопротивлением от 38-175 Ом*м, а толщина меняется от 9,6 до 14,2 м. Внутри ядра дамбы выделяется зона с удельным сопротивлением 90 Ом*м, которое авторы связывают с влажностью, фильтрацией и возможным просачиванием воды. В основании дамбы в пределах 15-20 м залегают породы с высоким удельным сопротивлени- ем от 335 до 3999 Ом*м. Значения с низким удельным сопротивлением в ядре дамбы хорошо коррелируется с отрицательными значениями потенциалом ЕП. Авторы связывают такие зоны с фильтрационными процессами в ядре дамбы, которые в будущем могут привести к аварии.

В работе [24] приводится исследования по определению геофизическими методами физического состояния земляной плотины Вольф Крик в штате Миссури (США). Применялся комплекс геофизических методов: электрическая томография, индуцированная поляризация и метод естественного электрического поля. Комплексная интерпретация данных измерений свидетельствует, что в теле плотины существуют две области, связанные с фильтрационным процессом. Это зоны стыка плотины с коренными породами и вокруг выпускного дренажного канала. Данные зоны в геофизическом поле характеризуются пониженным значением удельного сопротивления и отрицательными значениями естественного поля. Авторы надеются, что данные исследования помогут владельцу плотины принять решения по минимизации процесса утечки.

Применение электрометрических методов для определения физического состояния плотин и дамб приводится и в других исследованиях $[25,26]$. Основными измеряемыми параметрами физического поля являются: удельное электрическое сопротивление, проводимость, поляризуемость и потенциал естественного поля. Если первые три параметра хорошо выявляют ослабленные и водонасыщенные зоны, то потенциал естественного поля определяет направление фильтрационного потока в теле плотины. Кроме электрометрических методов зарубежные исследователи предлагают применять сейсмические методы для определения структурного строения дамб или плотин. Все исследователи утверждают, что уровень современного состояния геофизики очень высок - подготовлена научная основа всех методов, созданы высокоточные измеряемые аппаратуры, программное обеспечение для обработки данных. Это позволяет решать проблемы диагностики физического состояния ГТС с применением геофизических методов.

Применение геофизических методов для оценки технического состояния ГТС в Республике Казахстан было отмечено в несколько работах $[27,28]$. В работе [27] приводятся результаты исследований методом радиолокационного зондирования технического состояния гидротехнических сооружений Капчагайского водохранилища на реке Или (Республика Казахстан). Исследования проводились на русловой и логовой плотинах. Результаты георадарных исследований свидетельствует о возможности применения георадаров для выделения с достаточной уверенностью ослабленных зон или зон повышенной влажности в теле плотин. Авторы предлагают для изучения динамики таких зон проводить мониторинговые исследования в течение нескольких лет.

Для обеспечения безопасной эксплуатации Мойнакской ГЭС (Республика Казахстан) важным элементом являются достоверные данные по наличию и 
глубине локальных обводненных зон, повышенной трещиноватости, как факторы, снижающие прочностные свойства горных пород в прикровельной части деривационного туннеля [28].

Для выполнения данной задачи на площади $120 \times 320$ м проведен комплекс геофизических съемок: площадная магнитная съемка, профильная электроразведка методом сопротивлений и сейсморазведка МПВ. Результаты исследований свидетельствуют (рис. 1), что зоны разлома повышенной трещиноватости довольно хорошо выделяются пониженным значением магнитного поля, а локальные зоны - повышением электропроводности разреза и снижением в них граничной скорости упругих волн.
В ходе выполнения работ получены следующие результаты:

- по данным магнитометрической съёмки уточнена тектоническая обстановка по площадкам, включающим пикеты туннеля, в которых были установлены вывалы горных пород из его кровли. В целом по данным магнитометрических съёмок была создана фактурная основа для уточнения природы геоэлектрических и сейсмических аномальных эффектов по опорным профилям. Полученные данные могут быть использованы при необходимости детальных инженерно-геологических съёмок по обследованным интервалам створа туннеля;

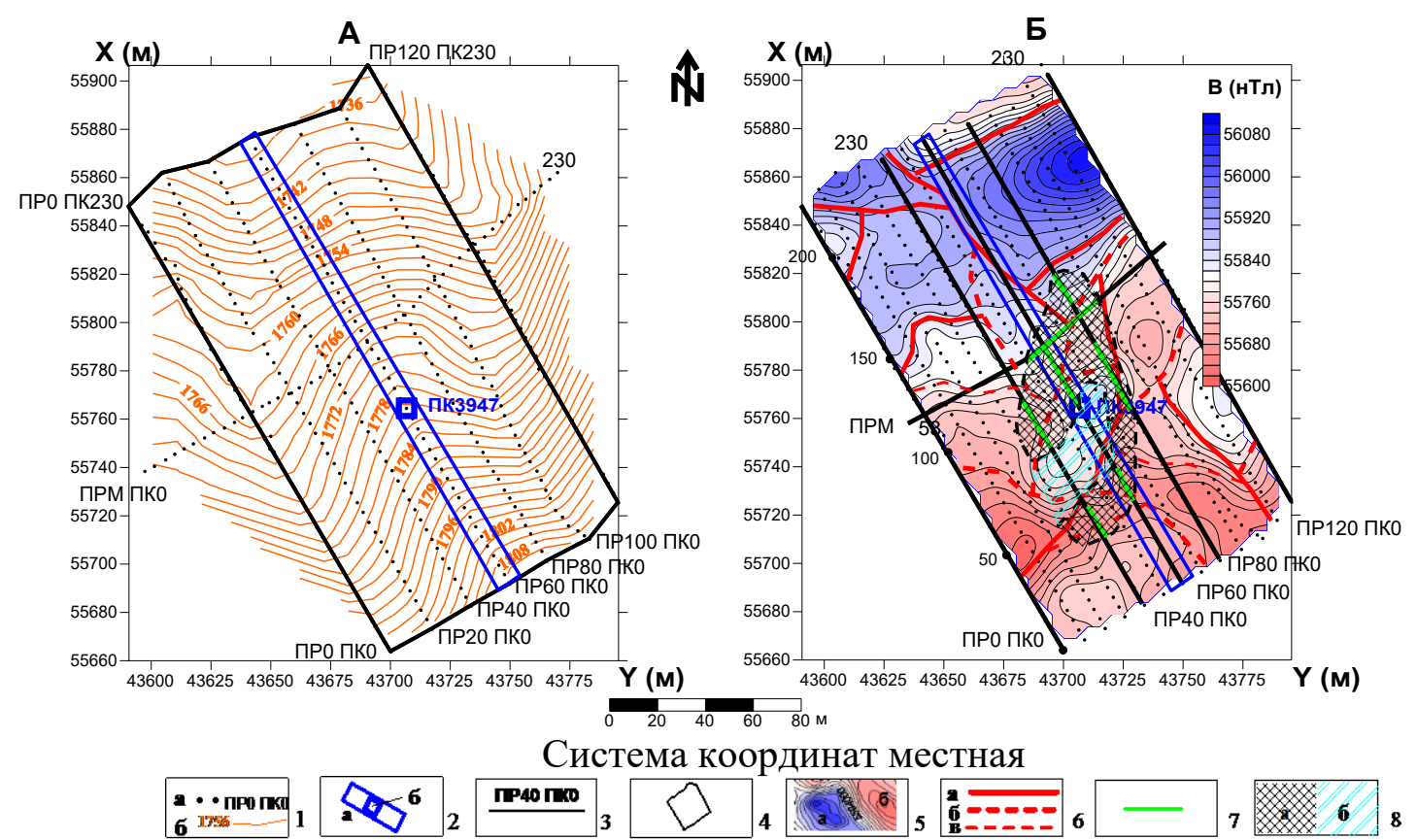

Рис. 1. Фрагмент деривационного туннеля Мойнакской ГЭС (ПК 3947). Схема отработки площадки комплексом геофизических методов (А) и её тектоническое строение (Б) по данным магнитометрической съёмки: 1) точки привязки пунктов геофизических наблюдений (а) и изолинии рельефа дневной поверхности (б); 2) фрагмент деривационного туннеля (а) и положение ПК 3947 (б); 3) профили электроразведочных и сейсморазведочных съёмок; 4) контур участка магнитометрической съёмки; 5) области аномально повыменных (a) и пониженных (б) значений модуля полного вектора магнитной индукции; б) гранищы блоков магматических пород с различными магнитными свойствами: основные (а), второстепенные (б) и предполагаемые (в); 7) зоны пониженной граничной скорости на линии опорных профилей; 8) зоны пониженной (а) и повышенной (б) граничной скорости около ПК 3947

Fig. 1. Fragment of diversion tunnel of Moinak Hydro Power Station (PK 3947). Scheme of site working-off by the complex of geophysical methods (A) and its tectonic structure (Б) according to magnetometric survey: 1) anchor geophysical observations points (a) and isolines of surface relief (б); 2) fragment of derivational tunnel (a) and position of PK 3947 (б); 3) profiles of electrical and seismic surveys; 4) contour of magnetometric survey plot; 5) areas of abnormally increased (a) and reduced (6) module of absolute magnetic induction vector; 6) borders of igneous rocks blocks with various magnetic properties: main (a), secondary (6) and probable (6); 7) reduced boundary speed zones on the reference profiles line; 8) zones of reduced (a) and increased (6) boundary velocity near PK3947

- по сети опорных профилей методами электроразведки и сейсморазведки на каждой площадке проведена оценка глубинности и обводнённости выявленных тектонических структур (рис. 2). По наличию таких структур вблизи заданных пикетов створа туннеля и характерным особенностям их проявления в геофизических полях дана вероятностная оценка им как факторам, способствующим образо- ванию вывалов горных пород из кровли туннеля. При этом явных признаков пустот не обнаружено.

- однако в районах, расположенных в зонах влияния тектонических структур, по геофизическим данным признано, что такие структуры могут выступать в качестве фактора, способствующего образованию вывалов горных пород из кровли туннеля. 


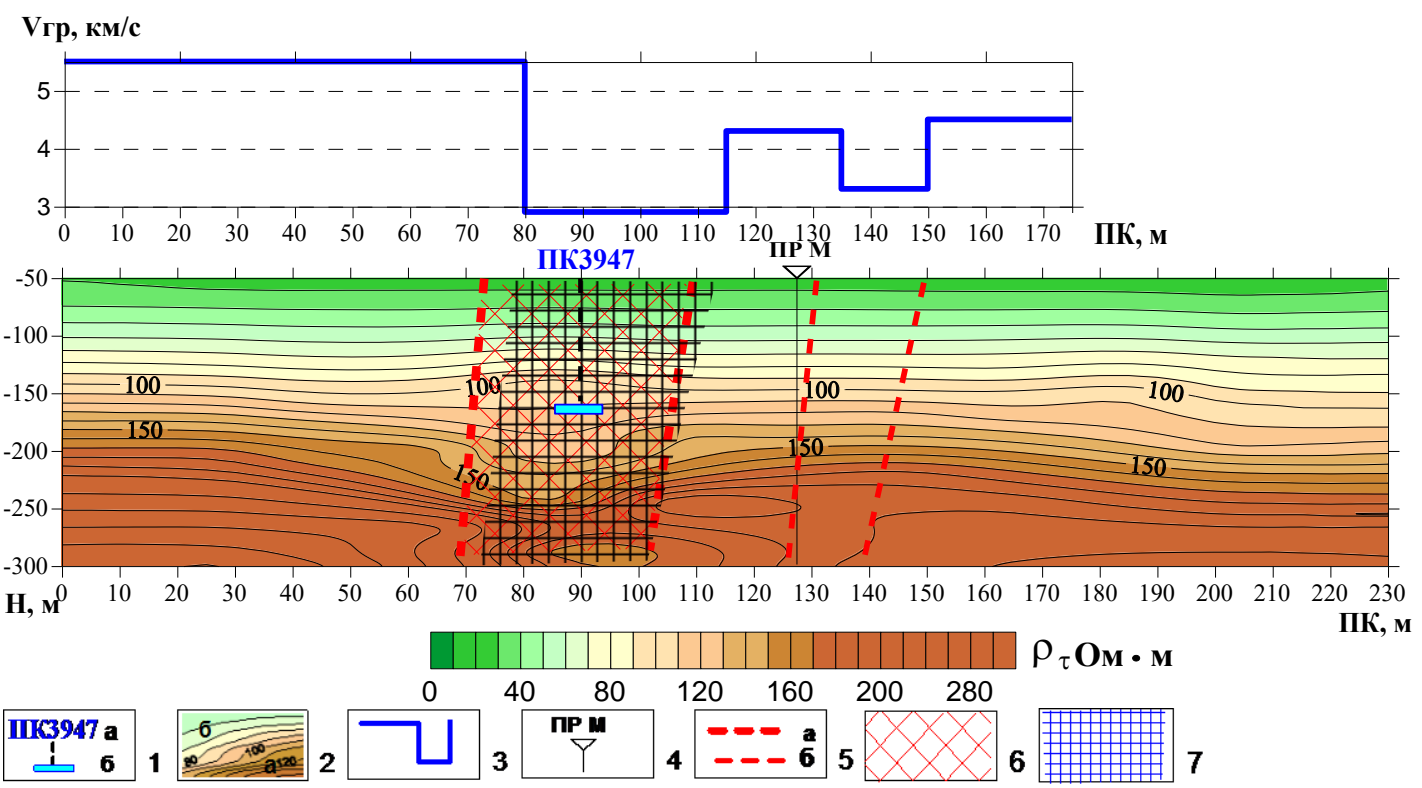

Pис. 2. Деривационный туннель Мойнакской ГЭС (ПК 3947). Оиенка обводнённой тектонической трещиноватости скального фундамента по линии профиля 80: 1) пикет деривационного туннеля (а) и предполагаемых зон вывала (б); 2) изолинии электрического сопротивления; 3) графики граничной скорости по кровле скальных пород; 4) точка пересечения геофизических профилей; 5) разломы по данным электрического сопротивления: уверенно выделенные (а) и предполагаемые (б); 6) обводненные зоны с повышенной электропроводностью: уверенно выделенные (а) и предполагаемые (б); 7) зона обводнённой тектонической трещиноватости по данным электроразведки и сейсморазведки

Fig. 2. Diversion tunnel of Moinak Hydro Power Station (PK 3947). Assessment of water-bearing tectonic rock fracturing of rock foundation based by the profile line 80: 1) picket of derivational tunnel (a) and probable inrush zones (6); 2) resistivity isolines; 3) boundary velocity graphs along the rock roof; 4) intersection points of geophysical profiles; 5) faults according to electrical resistivity: confidently identified (a) and probable (6); 6) water-bearing zones with increased electrical conductivity: confidently identified (a) and probable (б); 7) water-bearing tectonic fracture zones according to electrical and seismic data

\section{Обоснование оптимального комплекса геофизических методов при диагностике и прогнозировании технического состояния грунтовых плотин в Республике Казахстан}

Как было описано выше, задача оценки уровня безопасности ГТС может быть решена при помощи проведения комплексных геофизических исследований. Из анализа работ [15-28] по применению геофизических методов контроля устойчивости, безопасно- сти и прогноза технического состояния ГТС следует, что в основном применяются электроразведочные методы сопротивлений и ЕП, сейсмическая разведка в модификации МОВ и МПВ и георадарные исследования. В табл. 1 приводятся физические предпосылки применения инженерно-геофизических методов при обследовании плотин земляного типа.

Таблица 1. Физические предпосылки применения инженерно-геофизических методов для определения ослабленных и влагонасыщенных зон

Table 1. Physical prerequisites for using engineering-geophysical methods to determine the weakened and watersaturated zones

\begin{tabular}{|c|c|c|}
\hline $\begin{array}{l}\text { Эффекты и процессы } \\
\text { Effects and processes }\end{array}$ & $\begin{array}{c}\text { Проявление в физических характеристиках } \\
\text { Manifestation in physical characteristics }\end{array}$ & $\begin{array}{l}\text { Методы изучения } \\
\text { Study methods }\end{array}$ \\
\hline $\begin{array}{l}\text { Ослабленные водонасыщенные } \\
\text { зоны, трещины } \\
\text { Weakened water-saturated zones, } \\
\text { cracks }\end{array}$ & $\begin{array}{l}\text { Снижение скорости упругих волн, плотности, } \\
\text { повышение пористости } \\
\text { Elastic waves and density speed reduction, porosity } \\
\text { increase }\end{array}$ & $\begin{array}{l}\text { Сейсморазведка } \\
\text { Seismic exploration }\end{array}$ \\
\hline $\begin{array}{l}\text { Влагонасыщенные зоны в теле } \\
\text { плотины } \\
\text { Wet areas in the dam body }\end{array}$ & $\begin{array}{l}\text { Локальное повышение электропроводности и } \\
\text { поляризуемости } \\
\text { Local increase of electrical conductivity and } \\
\text { polarizability }\end{array}$ & $\begin{array}{l}\text { Электроразведка методом сопротивлений } \\
\text { Electrical Resistance Exploration }\end{array}$ \\
\hline $\begin{array}{l}\text { Фильтрационные процессы в теле } \\
\text { плотины } \\
\text { Filtration processes in the dam body }\end{array}$ & $\begin{array}{l}\text { Уменьшение или увеличение фильтрационного } \\
\text { поля } \\
\text { Decrease or increase of filtration field } \\
\end{array}$ & $\begin{array}{l}\text { Электроразведка методом естественного } \\
\text { электрического поля } \\
\text { Natural electric field electrical exploration } \\
\end{array}$ \\
\hline $\begin{array}{l}\text { Влагонасыщенные зоны в теле } \\
\text { плотины } \\
\text { Wet areas in the dam body }\end{array}$ & $\begin{array}{l}\text { Увеличение диэлектрической проницаемости } \\
\text { среды } \\
\text { Increase of dielectric permittivity }\end{array}$ & $\begin{array}{l}\text { Георадиолокационное зондирование } \\
\text { GPR sounding }\end{array}$ \\
\hline
\end{tabular}


Комплексы геофизических методов основываются на петрофизических свойствах горных пород, слагающих тело ГТС (табл. 2) [29], (табл. 3) [30].

Таблица 2. Удельные электрические сопротивления (УЭС) некоторых осадочных горных пород

Table 2. Specific electrical resistivity (SER) of some sedimentary rocks

\begin{tabular}{|l|c|c|c|}
\hline \multirow{2}{*}{$\begin{array}{c}\text { Наименование горной породы } \\
\text { Rock name }\end{array}$} & \multicolumn{3}{|c|}{ УЭС, Ом*м/SER, Om*m } \\
\cline { 2 - 4 } & $\begin{array}{c}\text { мин } \\
\text { min }\end{array}$ & $\begin{array}{c}\text { Типичное } \\
\text { typical }\end{array}$ & $\begin{array}{c}\text { макс } \\
\text { max }\end{array}$ \\
\hline Глины/Clay & 5 & 10 & 15 \\
\hline Суглинки/Loam & 15 & 30 & 50 \\
\hline Супеси/Sandy loam & 30 & 50 & 80 \\
\hline $\begin{array}{l}\text { Пески водонасыщенные } \\
\text { Saturated sands }\end{array}$ & 50 & 80 & 200 \\
\hline $\begin{array}{l}\text { Пески слабо увлажненные } \\
\text { Slightly wet sands }\end{array}$ & 100 & 150 & 500 \\
\hline Пески сухие/Dry sands & 200 & 500 & 10000 \\
\hline Дресва/ Coarse sand & 30 & 50 & 500 \\
\hline $\begin{array}{l}\text { Вечномерзлые породы } \\
\text { различной льдистости } \\
\text { Регтаfrost rocks of various ice content }\end{array}$ & 500 & - & 80000 \\
\hline
\end{tabular}

Таблица 3. Изменение плотности, пористости и скоростей упругих волн для осадочных горных пород и сред

Table 3. Changes of density, porosity and elastic wave velocities for sedimentary rocks and media

\begin{tabular}{|c|c|c|c|c|c|}
\hline \multirow{3}{*}{$\begin{array}{c}\text { Породы } \\
\text { Rocks }\end{array}$} & \multirow{3}{*}{ 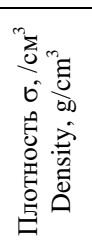 } & \multirow{3}{*}{ 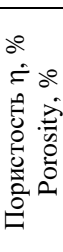 } & \multicolumn{3}{|c|}{$\begin{array}{l}\text { Скорости упругих волн } \\
\text { Velocities of elastic waves }\end{array}$} \\
\hline & & & \multicolumn{2}{|c|}{$\mathrm{V}_{\mathrm{p}}, \mathrm{KM} / \mathrm{c}(\mathrm{km} / \mathrm{s})$} & \multirow{2}{*}{ 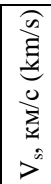 } \\
\hline & & & $\begin{array}{c}\text { Газонасы- } \\
\text { щенные } \\
\text { Gas saturated }\end{array}$ & $\begin{array}{c}\text { Водонасы- } \\
\text { щенные } \\
\text { Water } \\
\text { saturated }\end{array}$ & \\
\hline $\begin{array}{l}\text { Осадочные } \\
\text { Скальные и полу- } \\
\text { скальные } \\
\text { Sedimentary } \\
\text { Rock and half rock } \\
\text { известняк } \\
\text { limestone } \\
\text { доломит } \\
\text { dolomite } \\
\text { мергель/marl } \\
\text { песчаники } \\
\text { sandstones }\end{array}$ & $\begin{array}{l}2,6 \\
2,7 \\
2,4 \\
2,5\end{array}$ & $\begin{array}{l}2-25 \\
2-17 \\
5-35 \\
2-35\end{array}$ & $\begin{array}{c}2 \\
1 \\
1,5 \\
1\end{array}$ & $\begin{array}{c}6 \\
5,5 \\
4,5 \\
4,5\end{array}$ & $\begin{array}{c}3 \\
2,5 \\
2 \\
1\end{array}$ \\
\hline $\begin{array}{l}\text { Песчано- } \\
\text { обломочные } \\
\text { (рыхлые) } \\
\text { гравийно- } \\
\text { галечные } \\
\text { пески } \\
\text { Sandy-clastic } \\
\text { (loose) } \\
\text { gravel and pebble } \\
\text { sands }\end{array}$ & $\begin{array}{c}3 \\
1,3-2,0\end{array}$ & $\begin{array}{l}2-20 \\
2-40\end{array}$ & $\begin{array}{l}0,8 \\
0,5\end{array}$ & $\begin{array}{c}2,5 \\
2\end{array}$ & $\begin{array}{l}0,5 \\
0,2\end{array}$ \\
\hline $\begin{array}{l}\text { Пластичные } \\
\text { (глинистые) } \\
\text { (глина, аргиллит) } \\
\text { Plastic (clay) (clay, } \\
\text { mudstone) }\end{array}$ & $1,2-2,4$ & $2-40$ & 1,5 & 2,5 & 0,4 \\
\hline
\end{tabular}

Характеристики петрофизических свойств пород, слагающих тело насыпных ГТС (табл. 2, 3), являются основанием применения геофизических методов: а) электроразведки; б) сейсморазведки; в) георадарного зондирования.
Теоретические основы инженерно-геофизических и георадиолокационных методов при решении инженерно-геологических задачи приводятся в [31-33].

Учитывая богатый опыт исследователей данной проблемы из ближнего и дальнего зарубежья, планируется распространить применение данных геофизических методов при обследовании состояния грунтовых плотин в Республике Казахстан.

\section{Оценка состояния безопасности и управления гидротехническими сооружениями на основе создания базы данных}

На наш взгляд, для оценки безопасности ГТС необходимо использовать всю накопленную в процессе эксплуатации ГТС информацию. Большие объемы этой информации необходимо хранить в памяти вычислительных комплексов по специальным правилам и принципам, позволяющим эффективно использовать их для обработки и интерпретации с целью дальнейшего прогнозирования состояния ГТС и принятия оптимального управленческого решения. При этом очень важно, чтобы организация данных и их хранение в различных технических средствах были выполнены по единой технологии, обеспечивая их использования для решения поставленных задач. Тогда задача сводится к организации баз данных (БД) и системы управления базами данных.

Основным назначением БД является накопление информации о техническом состоянии ГТС. Всю информацию, в том числе об инцидентах, необходимо перевести и сохранить в цифровом формате для анализа и использования при решении конкретных задач, возникающих в процессе эксплуатации ГТС. База данных должна на системной основе постоянно пополняться новыми данными. Чем больше информации о ГТС, тем большую ценность данные базы будут представлять. Для оценки опасности возникновения аварийных ситуаций разрабатывается база данных ГТС, структура и состав которой приведены в работе [34]. В работе [35] авторы предлагают интегрировать получение оперативной информации по результатам комплексных исследований ГТС в БД для дальнейшей обработки и сравнения с нормативными данными. Это позволит провести оценку текущего состояния ГТС и принятие организационных мер по предотвращению тяжелых последствий возможных аварий. Следует отметить, что создание БД потребует разработки и совершенствования нормативных документов по сбору и систематизации данных по ГТС и информации по мониторингу их состояния. Также потребуется принятие организационных мер в работе организаций, эксплуатирующих ГТС, что, соответственно, должно быть подкреплено дополнительным финансированием. В конечном итоге эти мероприятия приведут к существенному улучшению ситуации с безопасностью эксплуатации ГТС.

\section{Выводы}

1. Проведено обобщение и анализ причин аварии на гидротехнических сооружениях различного типа в странах дальнего и ближнего зарубежья и Респуб- 
лики Казахстан. Дается оценка причин аварий, связанных с переливом, проблемами состояния плотины, плохим управлением, стихийными бедствиями и др. Отмечено, что в основном аварии происходят на земляных плотинах с высотой меньше 15 м (50,8 \%) и с высотой 15-30 м $(22,8$ \%). Причинами являются: перелив и проблемы, связанные с состоянием плотины. Определены опасные места, или зоны риска, в теле плотины: основание плотины, нисходящий склон и водосброс.

2. Применяемые в настоящее время натурные и визуальные наблюдения не дают полной картины технического состояния плотины. Необходимо использование современных достижений науки и техники в области инженерно-геологических изысканий. Таковыми являются геофизические методы неразрушающего контроля за состоянием плотин.

3. На опыте зарубежных исследователей гидротехнических сооружений по разработке комплексных инженерно-геофизических изысканий для диагностики технического состояния гидротехнических сооружений выбран оптимальный комплекс геофизических методов. В комплекс входят следующие методы: электроразведка (метод сопротивлений) и метод естественного электрического поля; сейсмическая разведка и георадарная съёмка. Преимуществом применения геофизических методов обследования является то, что на основе измеренных данных геофизических полей можно построить физико-геологическую модель, харак-

\section{СПИСОК ЛИТЕРАТУРЫ}

1. Свод правил: СП 58.13330.2012 Гидротехнические сооружения. Основные положения. Актуализированная редакция СНиП 33-01-2003. - М.: Федеральный центр нормирования, стандартизации и технической оценки соответствия в строительстве, 2012. -2 с.

2. Разработка и создание комплекса мероприятий по обеспечению безопасности гидротехнических сооружений / под ред. P.P. Ходжаева. - Алматы: La Creation, 2014. - 428 c.

3. Шибутова Л. Вопрос предупреждения паводков в Казахстане: статистика разрушений // Regnum. 2017. URL: https:// regnum.ru/news/economy/2279631.html/ (дата обращения: 19.08.2019)

4. Нарбаев М. Обзор деятельности по обеспечению безопасности гидротехнических сооружений в Казахстане // Международный семинар по безопасности гидротехнических сооружений. - СПб., 2017. URL: http://kazaral.org/obzor-deyatelnosti-poobespecheniyu-bezopasnosti-gidrotexnicheskix-sooruzhenij-vkazaxstane/ (дата обращения: 19.08.2019).

5. Zhang M., Xu Y., Jia J.S. Analysis of earth dam failures - a database approach // ISGSR 2007 First International Symposium on Geotechnical Safety \& Risk. - Shanghai, 2007. - V. 3 (3). P. 184-189.

6. Vogel A. Safety investigations of accidents of dam constructions // Proc. of the 24th European Safety, Reliability \& Data Association Seminar on Safety Investigations of Accidents. - Petten, Netherlands: JRC, 2003. - P. 144-151.

7. Singh V.P. Dam breach modeling technology // Water Science and Technology Library. - 1996. - P. 62-100.

8. Biswas A.K., Chatterjee S. Dam disasters - an assessment // Engineering Journal. - 1971. - V. 54 (3). - P. 3-8.

9. Johnson F.A., Illes P.A. Classification of dam failures // Water Power and Dam Construction. - 1976. - V. 28 (12). - P. 43-45. теризующую неоднородность тела насыпной плотины, т. е. внутреннее строение плотины, и дать оценку его состояния.

4. Практически все исследователи физического и технического состояния гидротехнических сооружений геофизическими методами особо выделяют метод естественного электрического поля. Аномальные его значения на поверхности связаны с водонасыщенностью грунтов и фильтрационными процессами, слагающими тело плотины. Для раннего выявления таких опасных зон предлагается проводить режимные наблюдения. Выбор режима наблюдений зависит от поставленной задачи; режимы могут быть сезонные (весна, лето, осень) или длящиеся несколько лет.

5. Для эффективного управления техническим состоянием гидротехнических сооружений предлагается создание базы данных гидротехнических сооружений. В основу базы данных должны входить: информация инженерно-геологического, геофизического, геодезического содержания, данные по визуальным и натурным наблюдениям, данные контрольно-измерительной аппаратуры об инцидентах на гидротехнических сооружениях, а также о ремонтно-восстановительных работах.

6. Опыт различных исследователей по применению геофизических методов с целью оценки технического состояния ГТС будет опробован на земляных плотинах в Республике Казахстан в рамках грантового проекта Министерства образования и науки Республики Казахстан.

10. Foster M., Fell R., Spannagle M. The statistics of embankment dam failures and accidents // Canadian Geotechnical Journal. 2000. - V. 37. - № 5. - Р. 1000-1024.

11. Черных О.Н., Доронкина О.А., Алтунин В.И. Анализ и оценка технического состояния грунтовых плотин по результатам натурных исследований // Роль природообустройства в обеспечении устойчивого функционирования и развития экосистем: Материалы международной научно-практической конференции. - М., 2006. - Т. 2. - С. 527-533.

12. Обследование гидротехнических сооружений при оценке их безопасности / под ред. Г.М. Каганов, В.И. Волков, О.Н. Черных. - М.: Московский государственный университет природообустройства, 2001. - 60 с.

13. Результаты натурного обследования состояния постоянной плотины Ташлыкского водоема-охладителя ЮжноУкраинской АЭС / В.Ю. Егупов, А.И. Бондаренко, А. Волкова, О.В. Кичаева // Будівельні конструкції. - 2016. - Вип. 83 (2). C. 591-598.

14. Кусаинов А.Б. Обследование гидротехнических сооружений с целью оценки безопасности. - Кокшетау: Кокшетауский технический университет Министерства по чрезвычайным ситуациям Республики Казахстан, 2013. - 41 с.

15. Определение физико-механических свойств грунтов при оценке состояния гидротехнических сооружений методами неразрушающего контроля / А.М. Пригара, А.В. Татаркин, А.В. Пенский, Б.М. Осовецкий, А.В. Коноплев // Научный журнал Кубанского государственного аграрного университета. 2012. - № 84 (10). URL: http://ej.kubagro.ru/2012/10/pdf/13.pdf (дата обращения: 20.06.2019).

16. Инженерно-геологическая оценка гидротехнических сооружений методами неразрушающего контроля / А.М. Пригара, Р.И. Царев, А.В. Коноплев, О.Г. Пенский, Б.М. Осовецкий // Фундаментальные исследования. - 2014. - № 11-2. С. 348-352. 
17. Диагностика состояния земляных плотин методами неразрушающего контроля / В.П. Колесников, А.В. Татаркин, А.М. Пригара, А.В. Коноплев // Геология и полезные ископаемые Западного Урала: материалы региональной научнопрактической конференции. - Пермь: Пермский университет, 2009. - C. $257-262$.

18. Технология комплексных инженерно-геофизических изысканий для диагностики состояния гидротехнических сооружений В.П. Колесников, А.В. Коноплев, А.М. Пригара, А.В. Татаркин // Современные проблемы науки и образования. - 2012. - № 6 URL: https://www.science-education.ru/ru/article/ view?id=7839 (дата обращения: 10.10.2018).

19. Динамика физического состояния ослабленных зон насыпной плотины Иркутской ГЭС за период 2002-2012 гг. / В.И. Джурик, А.Ю. Ескин, С.П. Серебренников, Е.В. Брыжак // Известия Иркутского государственного университета: Серия «Науки о Земле». - 2014. - Т. 8. - С. 35-41.

20. Geophysical evaluation of the inner structure of a historical earthfilled dam / D. Zumr, V. David, J. Krasa, J. Nedved // Proceedings. 2018. - V. 2. - 664 p. URL: https://www.mdpi.com/25043900/2/11/664/notes (дата обращения: 23.07.2019).

21. Sentenac P., Benes V., Keenan H. Reservoir assessment using noninvasive geophysical techniques // Environmental Earth Sciences. 2018. URL: https://link.springer.com/content/pdf/10.1007\% 2Fs12665-018-7463-x.pdf (дата обращения: 23.07.2019).

22. Monitoring of seepages around dams using geophysical methods: a brief review / O.T. Kayode, A.M. Odukoya, T.A. Adagunodo, A.A.Adeniji // IOP Conference Series: Earth and Environmental Science. - 2018. - V. 173. - P. 493-499. URL https://iopscience.iop.org/article/10.1088/17551315/173/1/012026/pdf (дата обращения: 13.09.2019).

23. Evaluation of subsurface conditions by geophysical methods at Ureje Earth Dam Embankment, Ado-Ekiti, Southwestern Nigeria a case study / J.O. Fatoba, A.B. Eluwole, O.L. Ademilua, O.A. Sanuade // Indian Journal of Geosciences. - 2018. - V. 72. № 4. - P. 275-282.

24. Dam seepage investigation of an Earthfill Dam in Warren County, Missouri using geophysical methods / S.C. Nwokebuihe, A.M. Alotaibi, A. Elkrry, E.V. Torgashov, N.L. Anderson // AIMS Geosciences. - 2017. - V. 3 (1). - P. 1-13. URL: https://www. aimspress.com/fileOther/PDF/geosciences/geosci-03-00001.pdf (дата обращения: 13.09.2019).

25. Camarero P.L., Moreira C.A. Geophysical investigation of earth dam using the electrical tomography resistivity technique // REM - International Engineering Journal. - 2017. - V. 70. - № 1.
URL: http://www.scielo.br/pdf/remi/v70n1/2448-167X-remi-7001-0047.pdf (дата обращения: 13.09.2019).

26. Seepage investigation on an existing dam using integrated geophysical methods / N.K. Olasunkanmi, A. Aina, S. Olatunji, M. Bawalla // Journal of Environment and Earth Science. 2018. - V.8. - № 5. URL: https://www.researchgate.net/ publication/329443608 (дата обращения: 10.10.2019).

27. Бибосынов А., Шигаев Д.Т., Кирсанов А.В. Неразрушающий метод исследовании Капчагайского гидротехнического сооружения // Известия Национальной академии наук Республики Казахстан: Серия физико-математическая. - 2015. T. $6(421)$. - C. 5-11.

28. Шайторов В.Н., Ахметов Е.М., Алдабергенова Г.И. Опыт применения геофизических методов при изучении тектонического строения разреза в створе деривационного туннеля Мойнакской ГЭС // Известия Национальной академии наук Республики Казахстан: серия геологии и технических наук. 2017. - T. 1 (421). - C. 87-95.

29. Вертикальное электрическое зондирование / под ред. И.Н. Модина. - М.: Московский государственный университет, 2007. $-28 \mathrm{c}$.

30. Хмелевской В.К. Геофизические методы исследования земной коры. Кн. 2. Региональная, разведочная, инженерная и экологическая геофизика. - Дубна: Международный университет природы, общества и человека «Дубна», 1999. - 28 с.

31. Огильви А.А. Основы инженерной геофизики. - М.: Изд-во «Недра», 1990. - 501 с.

32. Ляховицкий Ф.М., Хмелевской В.К., Ященко З.Г. Инженерная геофизика. - М.: Изд-во «Недра», 1989. - 252 с.

33. Владов М.Л., Золотарев В.П., Старовойтов А.В. Методическое руководство по проведению георадиолокационных исследований. - М.: МГУ, 1997. -68 с.

34. Состав и структура электронной базы гидротехнических сооружений водохранилищ Республики Беларусь / Г.И. Касперов, В.Е. Левкевич, С.М. Пастухов, А.В. Бузук // Труды Белорусского государственного технологического университета. 2013. - № 2. - C. 232-233.

35. Применение современных методов для комплексных исследований состояния гидротехнических сооружений региона Баренцева моря / Н.Н. Мельников, А.И. Калашник, Н.А. Калашник, Д.В. Запорожец // Вестник Мурманского государственного технического университета. - 2017. - Т. 20. - № 1 (1). C. $13-20$.

\section{Информация об авторах}

Axметов E.M., кандидат геолого-минералогических наук, доцент, ведущий научный сотрудник, Национальный центр по комплексной переработке минерального сырья Республики Казахстан.

Асемов К.М., главный специалист, Национальный центр по комплексной переработке минерального сырья Республики Казахстан.

жуматаева M.O., ведущий специалист, Национальный центр по комплексной переработке минерального сырья Республики Казахстан. 
UDC 627.8.059: 550.8.04

\title{
RESEARCH OF ACCIDENTS OF HYDRAULIC STRUCTURES AND SAFETY CONTROL METHODS
}

\author{
Yermek M. Akhmetov'1, \\ aem.47@mail.ru
}

\section{Kambar M. Assemov1, kassemov@kazkern.kz}

\author{
Marina O. Zhumataeva ${ }^{1}$, \\ j.marina07@rambler.ru
}

\author{
1 National center on complex processing of mineral raw materials of the Republic of Kazakhstan, \\ 67, Zhandossov street, Almaty, A10M6G5, Kazakhstan.
}

The relevance of the research. At present time the safety problems of water facilities, especially dams and other hydraulic structures are acute in the society. This is primarily due to the large economic, environmental and social losses, which lead to destruction of such facilities. In this regard, the need to minimize the likelihood of such events is obvious. This conclusion fully applies to the hydraulic structures in the Republic of Kazakhstan, most of which were built in the 60-80s of the last century and there were cases of emergency situations. The most significant of them are the breakthrough of earthen dams in Kyzylagash in 2010 and in Kokpekty in 2014. Recently, the use of new innovative methods for monitoring hydraulic structures, including geophysical methods, is intensively developing. Interpretation of geophysical measurements results can describe the structure and physicomechanical properties of the earth dams body in detail. This is the relevance of this work, which could be considered as a basis for further research and application of geophysical methods on the earth dams in the Republic of Kazakhstan.

The aim of the research is to select the optimal complex of geophysical methods for their subsequent testing at the earth hydraulic structures.

Object of the research is the causes of hydraulic structures accidents and the methods for their condition monitoring.

Methodology: analysis of the causes of hydraulic structures destruction, analysis of the informativeness of geophysical methods for dams structure studying with justification of the optimal complex for diagnosis and prediction of the earth dams technical condition.

As a result of study the optimal complex of geophysical methods was selected: electrical and seismic exploration, georadar sounding. This complex will be further tested on the earth dams.

\section{Key words:}

Hydraulic structures, safety, control methods, geophysical methods, optimal complex, earth dams in the Republic of Kazakhstan, databases.

\section{REFERENCES}

1. Svod pravil: SP 58.13330.2012 Gidrotekhnicheskie sooruzheniya. Osnovnye polozheniyaю Aktualizirovannaya redaktsiya SNiP 33 01-2003 [Code of practice: SP 58.13330.2012 Hydrotechnical structures. Basic provisionsю Updated version of SNiP 33-012003]. Moscow, Federal Center for Normalization, Standardization and Technical Conformity Assessment in Construction, 2012. $2 \mathrm{p}$.

2. Razrabotka i sozdanie kompleksa meropriyatiy po obespecheniyu bezopasnosti gidrotekhnicheskikh sooruzheniy [Development and creation of a set of measures to ensure the safety of hydrotechnical structures]. Ed. by R.R. Hodzhaev. Almaty, La Creation, 2014. $428 \mathrm{p}$.

3. Shibutova L. Vopros preduprejdeniya pavodkov v Kazahstane: statistika razrusheniya [The issue of flood prevention in Kazakhstan: statistics of destructions]. Regnum, 2017. Available at: https://regnum.ru/news/economy/2279631.html/ (accessed $19 \mathrm{Au}-$ gust 2019).

4. Narbaev M. Obzor deyatelnosti po obespecheniyu bezopasnosti gidrotekhnicheskikh sooruzhenii v Kazakhstane [Overview of the safety of hydraulic structures in Kazakhstan. International workshop on the safety of hydraulic structures]. St. Petersburg, Russia, 2017. Available at: http://kazaral.org/obzor-deyatelnosti-poobespecheniyu-bezopasnosti-gidrotexnicheskix -sooruzhenij-vkazaxstane/ (accessed 19 August 2019).

5. Zhang M., Xu Y., Jia J.S. Analysis of earth dam failures - a database approach. ISGSR 2007 First International Symposium on Geotechnical Safety \& Risk. Shanghai, 2007. Vol. 3 (3), pp. 184-189.

6. Vogel A. Safety investigations of accidents of dam constructions. Proc. of the $24^{\text {th }}$ European Safety, Reliability \& Data Association Seminar on Safety Investigations of Accidents. Petten, Netherlands, JRC, 2003. pp. 144-151.
7. Singh V.P. Dam breach modelling technology. Water Science and Technology Library, 1996, pp. 62-100.

8. Biswas A.K., Chatterjee S. Dam disasters - an assessment. Engineering Journal, 1971, vol. 54 (3), pp. 3-8.

9. Johnson F.A., Illes P. A classification of dam failures. Water Power and Dam Construction, 1976, vol. 28 (12), pp. 43-45.

10. Foster M., Fell R., Spannagle M. The statistics of embankment dam failures and accidents. Canadian Geotechnical Journal, 2000, vol. 37, no. 5, pp. 1000-1024.

11. Chernykh O.N., Doronkina O.A., Altunin V.I. Analiz i otsenka tekhnicheskogo sostoyaniya gruntovykh plotin po rezultatam naturnykh issledovaniy [Analysis and assessment of technical condition of soil dams according to the results of field studies]. Rol prirodoobustroystva $v$ obespechenii ustoychivogo funktsionirovaniya $i$ razvitiva ekosistem. Materialy mezhdunarodnoy nauchno-prakticheskoy konferentsii [The role of environmental management in ensuring the sustainable functioning and development of ecosystems. Materials of the international scientific and practical conference]. Moscow, 2006. Vol. 2, pp. 527-533.

12. Obsledovanie gidrotekhnicheskikh sooruzheniy pri otsenke ikh bezopasnosti [Inspection of hydraulic structures in assessing their safety]. Eds. G.M. Kaganov, V.I. Volkov, O.N. Chernykh. Moscow, Moscow State University of Environmental Engineering, $2001.60 \mathrm{p}$.

13. Egupov V.Yu., Bondarenko A.I., Volkova A., Kichaeva O.V. Rezultaty naturnogo obsledovaniya sostoyaniya postoyannoy plotiny Tashlykskogo vodoema-okhladitelya Iuzhno-Ukrainskoy AES [Field survey findings of the permanent dam status of the Tashlyksky reservoir-cooler of the South Ukrainian NPP]. Budivelni konstruktsii, 2016, Iss. 83 (2), pp. 591-598.

14. Kussainov A.B. Obsledovanie gidrotehnicheskikh sooruzheniy s tseliyu otsenki bezopasnosti [Inspection of hydraulic structures to as- 
sess safety]. Kokshetau, Kokshetau Technical University of the Ministry of Emergencies of the Republic of Kazakhstan, 2013.41 p.

15. Prigara A.M., Tatarkin A.V., Pensky A.V., Osovetsky B.M., Konoplev A.V. Determination of physical and mechanical properties of soils when assessing the condition of hydraulic structures using non-destructive testing methods. Scientific journal of Kuban State Agrarian University, 2012, no. 84 (10). In Rus. Available at: http://ej.kubagro.ru/2012/10/pdf/13.pdf (accessed 20 June 2019).

16. Prigara A.M., Tsarev R.I., Konoplev A.V., Pensky O.G., Osovetsky B.M. Engineering and geological assessment of hydraulic structures with non-destructive testing methods. Basic research, 2014, no. 11-2, pp. 348-352. In Rus.

17. Kolesnikov V.P., Tatarkin A.V., Prigara A.M., Konoplev A.V. Diagnostika sostoyaniya zemlyanykh plotin metodami nerazrushayushchego kontrolya [Diagnosis of earth dams state by non-destructive testing methods]. Geologiya i poleznye iskopaemye Zapadnogo Urala. Materialy regionalnoy nauchnoprakticheskoy konferentsii [Geology and Minerals of the Western Urals. Materials of regional scientific and practical conference]. Perm, Perm University, 2009. pp. 257-262.

18. Kolesnikov V.P., Konoplev A.V., Prigara A.M., Tatarkin A.V Technology of complex engineering-geophysical surveys for diagnosing the state of hydraulic structures. Modern problems of science and education, 2012, no. 6. In Rus. Available at: https://www.science-education.ru/ru/article/view?id=7839 (accessed 10.10.2018).

19. Dzhurik V.I., Eskin A.Yu., Serebrennikov S.P., Bryzhak E.V. Dinamika fizicheskogo sostoyaniya oslablennykh zon nasypnoy plotiny Irkutskoy GES za period 2002-2012 gg. [Physical condition dynamics on the weakened zones of the bulk dam of the Irkutsk Hydroelectric Power Station for 2002-2012]. Bulletin of Irkutsk State University: Series of «Earth Sciences», 2014. vol. 8, pp. 35-41.

20. Zumr D., David V., Krasa J., Nedved J. Geophysical evaluation of the inner structure of a historical earth-filled dam. Proceedings, 2018, vol. 2, 664 p. Available at: https://www.mdpi.com/25043900/2/11/664/notes (accessed 23 July 2019).

21. Sentenac P., Benes V., Keenan H. Reservoir assessment using non-invasive geophysical techniques. Environmental Earth Sciences, 2018. Available at: https://link.springer.com/content/ pdf/10.1007\%2Fs12665-018-7463-x.pdf (accessed 23 July 2019).

22. Kayode O.T., Odukoya A.M., Adagunodo T.A., Adeniji A.A. Monitoring of seepages around dams using geophysical methods: a brief review. IOP Conference Series: Earth and Environmental Science, 2018, vol. 173, pp. 493-499. Available at: https://iopscience.iop.org/article/10.1088/17551315/173/1/012026/pdf (accessed 13 September 2019).

23. Fatoba J.O., Eluwole A.B., Ademilua O.L., Sanuade O.A. Evaluation of subsurface conditions by geophysical methods at Ureje Earth Dam Embankment, Ado-Ekiti, Southwestern Nigeria - a case study. Indian Journal of Geosciences, 2018, vol. 72, no. 4, pp. 275-282.

24. Nwokebuihe S.C., Alotaibi A.M., Elkrry A., Torgashov E.V., Anderson N.L. Dam seepage investigation of an earthfill dam in Warren County, Missouri using geophysical methods. AIMS Geosciences, 2017, vol. 3 (1), pp. 1-13. Available at:
https://www.aimspress.com/fileOther/PDF/geosciences/geosci-0300001.pdf (accessed 13 September 2019).

25. Camarero P.L., Moreira C.A. Geophysical investigation of earth dam using the electrical tomography resistivity technique. REM International Engineering Journal, 2017, vol. 70, no. 1. Available at: http://www.scielo.br/pdf/remi/v70n1/2448-167X-remi-70-010047.pdf (accessed 13 September 2019).

26. Olasunkanmi N.K., Aina A., Olatunji S., Bawalla M. Seepage investigation on an existing dam using integrated geophysical methods. Journal of Environment and Earth Science, 2018, vol. 8, no. 5. Available at: https://www.researchgate.net/publication/ 329443608 (accessed 10 October 2019).

27. Bibosynov A., Shigaev D.T., Kirsanov A.V. Non-destructive method for the study of the Kapchagai hydraulic structure. Proceedings of the National Academy of Sciences of the Republic of Kazakhstan: Physics and Mathematics Series, Almaty, 2015, vol. 6 (421), pp. 5-11. In Rus.

28. Shaitorov V.N., Akhmetov E.M., Aldabergenova G.I. The experience of applying geophysical methods in the study of the tectonic structure of a section in the alignment of the diversion tunnel of the Moinak Hydroelectric Power Station. Bulletin of the National Academy of Sciences of the Republic of Kazakhstan: Geology and technical sciences series, Almaty, 2017, vol. 1 (421), pp. 87-95. In Rus.

29. Vertikalnoe elektricheskoe zondirovanie [Vertical electrical sensing]. Ed. by I.N. Modin. Moscow, Moscow State University, 2007. $28 \mathrm{p}$.

30. Khmelevskoy V.K. Geofizicheskie metody issledovaniya zemnoy kory. Kn. 2: regionalnaya, razvedochnaya, inzhenernaya $i$ ekologicheskaya geofizika [Geophysical research methods of the earth's crust. B. 2. Regional, exploratory, engineering and environmental geophysics]. Dubna, International University of Nature, Society and Man «Dubna», 1999. $28 \mathrm{p}$.

31. Ogilvi A.A. Osnovy inzhenernoy geofiziki [Fundamentals of engineering geophysics]. Moscow, Nedra Publ., 1990. 501 p.

32. Lyakhovitsky F.M., Khmelevsky V.K., Yashchenko Z.G. Inzhenernaya geofizika [Engineering geophysics]. Moscow, Nedra Publ., 1989. $252 \mathrm{p}$

33. Vladov M.L., Zolotarev V.P., Starovoitov A.V. Metodicheskoe rukovodstvo po provedeniyu georadiolokatsionnykh issledovaniy [Guidance on conducting georadar research]. Moscow, Moscow State University, 1997. 68 p.

34. Kasperov G.I., Levkevich V.E., Pastukhov S.M., Buzuk A.V. The composition and structure of the electronic database for reservoirs of hydraulic structures of the Republic of Belarus. Proceedings of Belarusian State Technological University, 2013, no. 2, pp. 232233. In Rus.

35. Melnikov N.N., Kalashnik A.I., Kalashnik N.A., Zaporozhets D.V. Primenenie sovremennykh metodov dlya kompleksnykh issledovaniy sostoyaniya gidrotekhnicheskikh sooruzheniy regiona Barentseva moriya [Application of modern methods for comprehensive studies of the state of hydraulic structures in the Barents Sea]. Bulletin of the Murmansk State Technical University, 2017, vol. 20, no. $1 / 1$, pp. $13-20$

Received: 16 December 2019.

\section{Information about the authors}

Yermek M. Akhmetov, Cand Sc, associate professor, leading researcher, National center on complex processing of mineral raw materials of the Republic of Kazakhstan.

Kambar M. Assemov, chief specialist, National center on complex processing of mineral raw materials of the Republic of Kazakhstan.

Marina O. Zhumataeva, leading specialist, National center on complex processing of mineral raw materials of the Republic of Kazakhstan. 